\title{
Endoscopic Diagnosis of Leukemia in a Child with Acute Abdominal Pain
}

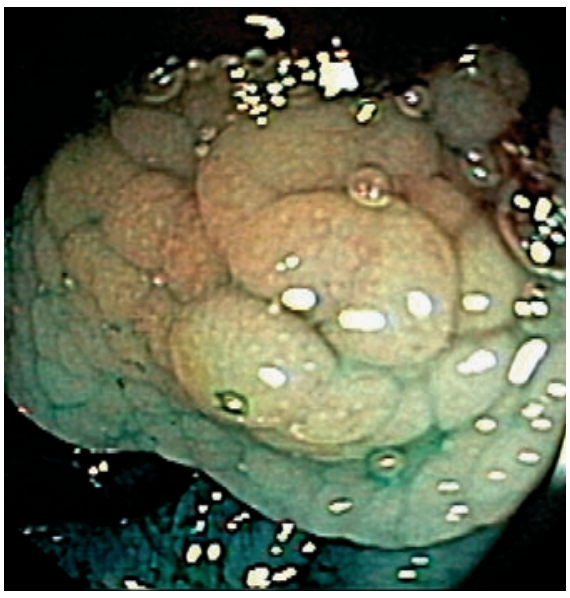

Figure 1 A 10-year-old girl with an unremarkable medical history presented with acute abdominal pain. She had had symptoms of general malaise, intermittent fever, and pain in the right-sided maxilla joint and in the elbow joint for 1 month. There was no diarrhea or rectal blood loss. She had lost $4 \mathrm{~kg}$ in weight, and was a moderately ill child with pinpoint localized tenderness in the right lower quadrant of the abdomen. A full blood count showed normal leukocyte differentiation. Abdominal ultrasonography revealed some thickening of the ileal wall. Infectious, immunological, and gastrointestinal causes or malignancy were considered. Colonoscopy was carried out to rule out inflammatory bowel disease. A sessile, hyperplastic polypoid lesion in an otherwise unremarkable colon was found, situated opposite the ileocecal valve.

\section{L. de Ridder, D. K. Bosman,}

M. A. Benninga, F. J. W. ten Kate, V. de Haas, J. A. J. M. Taminiau

Emma Children's Hospital, Academic Medical Center, Amsterdam, The Netherlands

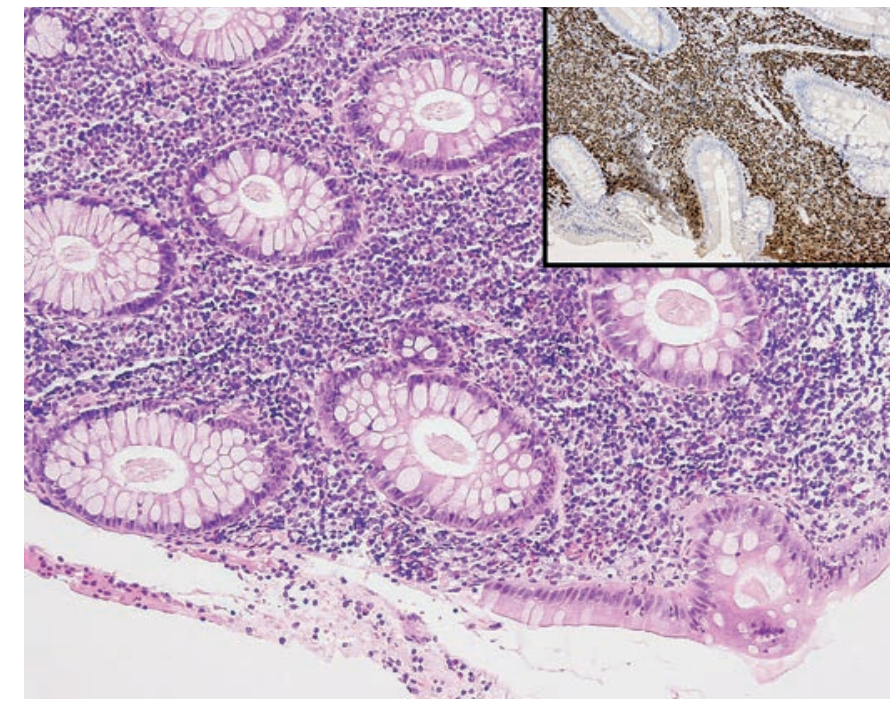

Figure 2 Histopathological examination of the polypoid lesion revealed a dense, atypical mononuclear infiltrate (hematoxylin-eosin, original magnification $50 \times$ ). A full blood count was repeated and, surprisingly, a $49 \%$ rate of blast cells was now found. Bone-marrow puncture revealed a $100 \%$ rate of blast cells. Pre-B-cell leukemia was diagnosed. Immunohistochemical studies of the biopsies from the polypoid lesion revealed CD10-positive B-cell proliferation. Inset: terminal deoxynucleotidyl transferase (TdT). Chemotherapy (vincristine, dexamethasone, asparaginase and triple intrathecal therapy) was started, and the patient's abdominal pain and other symptoms subsequently disappeared. After induction chemotherapy, the girl was in remission. As this case shows, a polypoid lesion in the gastrointestinal tract may be the first presentation of acute leukemia; awareness of this possibility may expedite the diagnosis.

Corresponding Author

\section{L. de Ridder, M.D.}

Emma Children's Hospital,

Academic Medical Centre, G8-205

Meibergdreef 9

1105 AZ Amsterdam

The Netherlands

Fax: + 31-20-6917735

E-mail: 1.deridder@amc.uva.nl 